\title{
Glucose intolerance during adjuvant chemotherapy for breast cancer
}

\section{Short communication}

There is considerable body of evidence to show that sizeable number of cancer patients have diabetes and these patients have poor outcome following chemotherapy for breast cancer. ${ }^{1}$ It is beleived that chemotherapy could influece glucose metabolism as dexamethasone is given to minimize side effects of chemo-therapy. ${ }^{2}$ In the present study blood glucose levels were monitored in with each cycle chemotherapy in 38 non-diabetic breast cancer patients. (mean age $\mathrm{SD}=54.4$ years [11.4]; mean body mass index $\mathrm{SD}=26.5 \mathrm{~kg} / \mathrm{m}^{2}$ [3.6]). The study was approved by the Institution Ethics Review Board after getting written informed consent from the patients.

The women received either six cycles of fluorouracil, epirubicin, cyclophosphamide (FEC) (18 women) or three cycles of FEC, followed by three cycles of docetaxel ( 20 women). Before each cycle of FEC chemotherapy, each woman received $8 \mathrm{mg}$ of dexamethasone (by oral administration). The women who were treated with docetaxel received $8 \mathrm{mg}$ of dexamethasone (by oral administration) 24hours, 12 hours, and immediately before receiving docetaxel (per the product specification). For each cycle of chemotherapy, the nonfasting blood glucose level was measured before the treatment cycle began, immediately after the prechemotherapy dexamethasone was administered but before the administration of chemotherapy, immediately after chemotherapy, and 10days after each chemotherapy cycle. ${ }^{3,4}$ Blood was drawn from these patients 12 hours of fasting and the samples were subjected blood glucose estimation by standarized glucose oxidase method. ${ }^{5}$

There was a statistically significant increase in blood glucose levels with later cycles among women who received the higher dose of dexamethasone in combination with docetaxel (cycle 5: P $<.001$; cycle 6: $\mathrm{P}=.002$ paired $\mathrm{t}$ tests) (Table 1 ). Before the first cycle of chemotherapy, none of the women had blood glucose levels in either the impaired glucose tolerance range (i.e., 7.8-11.1 $\mathrm{mmol} / \mathrm{L}$ ) or the diabetic range (i.e., $>11.1 \mathrm{mmol} / \mathrm{L}$ ). However, as the cycles progressed, an increasing number of women developed degrees of glucose intolerance: Seven women had blood glucose levels in the impaired tolerance range and eight women had levels within the diabetic range following the fifth chemotherapy cycle. Because these women were not diabetic before chemotherapy, it is likely that their hyperglycemia was associated with transient hyperinsulinemia.
Volume 6 Issue I - 2016

\section{Dhastagir Sultan S}

Melmaruvathur Adhiparasakthi Institute of Medical Sciences and Research, India

Correspondence: Dhastagir Sultan Sheriff, Melmaruvathur Adhiparasakthi Institute of Medical Sciences and Research, Melmaruvathur,TN, India, Email dhastagir@yahoo.ca

Received: September 09, 2016 | Published: November 08, 2016

High levels of insulin receptor, activated insulin and insulin like growth factor pathways and regulation sex hormones were demonstrated to be involved in breast cancer., ${ }^{1,4}$ There is a study which had shown a direct association between fasting serum insulin levels with cancer recurrence and higher mortality in a group of non diabetic women with early stage breast cancer. ${ }^{6,7}$ It is shown that sustained hyperglycemia, hyperinsulinemia and insulin resistance (IR) may be associated with cancer promotion and progression. Poor glycemic control which may lead to metabolic dysregulation creating proinflammatory condition. Chronic inflammation may induce oxidative stress in impaired glucose environment which may promote tumor progression. The insulin/IGF axis is deeply involved in diabetes-associated increased risk and progression of cancer, to such an extent that it has been demonstrated that cancer cells overexpress both insulin and IGF-1 receptors. ${ }^{8-12}$ It is also shown that fasting glucose is a risk factor for breast cancer. ${ }^{12}$ In general it could suggested that chronic alteration of glucose metabolism is related to breast cancer development.

Therefore transient hyperglycemia associated with chemotherapy may have an impact on the clinical efficay of chemotherapy and need further investigation to demonstrate the link between chemotherapy and glucose metabolism.

Table I Mean blood glucose level (SD) before the treatment cycle, after prechemotherapy dexamethasone but before chemotherapy, immediately after chemotherapy, and 10 days after chemotherapy

\begin{tabular}{lllll}
\hline Cycle & $\begin{array}{l}\text { Before Treatment } \\
\text { Cycle }\end{array}$ & $\begin{array}{l}\text { Immediately after Dexamethasone but } \\
\text { before Chemotherapy }\end{array}$ & $\begin{array}{l}\text { After Dexamethasone and } \\
\text { Chemotherapy }\end{array}$ & $\begin{array}{l}\text { I0 d after } \\
\text { Chemotherapy }\end{array}$ \\
\hline 1 & $5.4(1.1)$ & $4.2(0.7)$ & $5.3(2.0)$ & $5.4(0.7)$ \\
2 & $5.5(0.9)$ & $5.6(1.0)$ & & $5.5(0.8)$ \\
3 & $5.4(0.9)$ & $5.4(1.3)$ & $5.9(1.5)$ & $5.5(1.0)$ \\
4 & $5.9(0.9)$ & $6.0(1.6)$ & $6.4(1.8)$ & $5.8(1.4)$ \\
5 & $5.6(1.0)$ & $7.2(3.0)$ & $7.8(2.7)$ & $6.0(2.0)$ \\
6 & $5.4(0.8)$ & $8.2(2.7)$ & $8.1(3.1)$ & $6.0(1.2)$ \\
\hline
\end{tabular}

Glucose levels are expressed as $\mathrm{mmol} / \mathrm{L}$. 


\section{Acknowledgments}

None.

\section{Conflicts of interest}

Author declares there are no conflicts of interest.

\section{References}

1. Wolf I, Sadetzki S, Catane R, et al. Diabetes mellitus and breast cancer. Lancet Oncol. 2005;6(2):103-110.

2. Ioannidis J, Heskethh P, Lau J. Contribution of dexamethasone to control of chemotherapy-induced nausea and vomiting: a meta-analysis of randomised evidence. J Clin Oncol. 2000;18(19):3409-3422.

3. Munck A. Glucocorticoid inhibition of glucose uptake by peripheral tissues: old and new evidence, molecular mechanisms and physiological significance. Persp Med Biol. 1971;14(2):265-269.

4. Boyd D. Insulin and cancer. Integr Cancer Ther. 2003;2(4):315-329.

5. Wulaningsih W, Holmberg L, Garmo H, et al. Serum glucose and fructosamine in relation to risk of cancer. PLoS One. 2013;8(1):e54944.
6. Goodwin PJ, Ennis M, Pritchard KI, et al. Fasting insulin and outcome in early-stage breast cancer: results of a prospective cohort study. J Clin Oncol. 20(1):42-51.

7. Trédan $\mathrm{O}$, Galmarini $\mathrm{C}$, Patel $\mathrm{K}$, et al.Drug resistance and the solid tumor microenvironment. J Natl Cancer Inst. 2007;99(19):1441-1454.

8. Gouveri E, Papanas N, Maltezos E. The female breast and diabetes. The Breast. 2011;20(3):205-211.

9. Minicozzi P1, Berrino F, Sebastiani F, et al. High fasting blood glucose and obesity significantly and independently increase risk of breast cancer death in hormone receptor-positive disease. Eur J Cancer. 2013;49(18)3881-3888.

10. Ferroni P, Riondino S, Buonomo O, et al. Type 2 Diabetes and Breast Cancer: The Interplay between Impaired Glucose Metabolism and Oxidant Stress. Oxidative Medicine and Cellular Longevity. 2015:10.

11. Muti P, Quattrin T, Grant BJ, et al. Fasting glucose is a risk factor for breast cancer: a prospective study. Cancer Epidemiol Biomarkers Prev. 2002;11(11):1361-1368.

12. Boyle P, Koechlin A, Pizot C, et al. Blood glucose concentrations and breast cancer risk in women without diabetes: a meta-analysis. Eur $J$ Nutr. 2013;52(5):1533-1540. 